\title{
Optical closure experiments for biomass smoke aerosols
}

\author{
L. A. Mack ${ }^{1}$, E. J. T. Levin ${ }^{1}$, S. M. Kreidenweis ${ }^{1}$, D. Obrist ${ }^{2}$, H. Moosmüller ${ }^{2}$, K. A. Lewis ${ }^{3}$, W. P. Arnott ${ }^{3}$, \\ G. R. McMeeking ${ }^{1, *}$, A. P. Sullivan ${ }^{1}$, C. E. Wold ${ }^{4}$, W.-M. Hao ${ }^{4}$, J. L. Collett Jr. ${ }^{1}$, and W. C. Malm ${ }^{5}$ \\ ${ }^{1}$ Department of Atmospheric Science, Colorado State University, Fort Collins, CO, USA \\ ${ }^{2}$ Desert Research Institute, Nevada System of Higher Education, Reno, NV, USA \\ ${ }^{3}$ Department of Physics, University of Nevada, Reno, NV, USA \\ ${ }^{4}$ US Forest Service, RMRS Fire Sciences Laboratory, Missoula, MT, USA \\ ${ }^{5}$ Air Resources Division, US National Park Service, Fort Collins, CO, USA \\ *now at: Centre for Atmospheric Science, University of Manchester, Manchester, UK
}

Received: 1 March 2010 - Published in Atmos. Chem. Phys. Discuss.: 23 March 2010

Revised: 27 August 2010 - Accepted: 1 September 2010 - Published: 29 September 2010

\begin{abstract}
A series of laboratory experiments at the Fire Laboratory at Missoula (FLAME) investigated chemical, physical, and optical properties of fresh smoke samples from combustion of wildland fuels that are burned annually in the western and southeastern US The burns were conducted in the combustion chamber of the US Forest Service Fire Sciences Laboratory in Missoula, Montana. Here we discuss retrieval of optical properties for a variety of fuels burned in FLAME 2, using nephelometer-measured scattering coefficients, photoacoustically-measured aerosol absorption coefficients, and size distribution measurements. Uncertainties are estimated from various instrument characteristics and instrument calibration studies. Our estimates of single scattering albedo for different dry smoke samples varied from 0.428 to 0.990 , indicative of observed wide variations in smoke aerosol chemical composition. In selected case studies, we retrieved the complex refractive index from measurements but show that these are highly sensitive to uncertainties in measured size distributions.
\end{abstract}

\section{Introduction}

Absorbing aerosols represent large contributions to aerosol optical depth (AOD) attributed to "atmospheric brown clouds" (e.g., Ramanathan et al., 2007), which have been shown to have widespread effects on climate due to the surface dimming and atmospheric solar heating with which they are associated. Ramanathan and Feng (2009) discuss a variety of impacts attributable to atmospheric brown clouds:

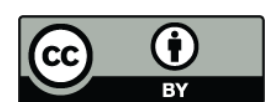

Correspondence to: S. M. Kreidenweis (sonia@atmos.colostate.edu) for example, absorption of light and the resulting heating affects atmospheric dynamics locally by stabilizing atmospheric temperature profiles and, on larger scales, by affecting monsoon circulations, and deposition of absorbing aerosols onto snow and ice can accelerate melting. As discussed by Bond (2007), annual mass emissions of carbonaceous aerosol species (organic carbon $[\mathrm{OC}]$ and elemental carbon [EC]) from open biomass burning are very large compared with total emissions from energy-related combustion, and thus should be considered in strategies aimed at reducing radiative forcing by warming aerosols. Optical properties of biomass burning aerosols at visible wavelengths are of interest since a large fraction of incoming solar energy is in this range (Chen and Bond, 2010), and since carbonaceous aerosols contribute to visibility degradation, sometimes in complex ways (Moosmüller, et al., 2009).

Calculated climate and visibility impacts of biomass burning aerosols are sensitive to the relative amounts of scattering and absorption, which in turn depend on the size distribution of particles and on composition (Chylek and Wong, 1995). Chen and Bond (2010) note the high variability observed in optical properties of particles emitted from biomass combustion, reflecting variations in fuel type and also in fuel size and combustion conditions. Further, optical properties are affected by the often complex shapes of combustion particles (Moosmüller, et al., 2009) and by water uptake at elevated relative humidities (Massoli et al., 2009).

In this study, we focus on contributing to the database of knowledge of optical properties of biomass burning particles that have not been processed in the atmosphere, via laboratory measurements made on dry particles within a few hours of emission from open burning. We further relate these optical properties to measured bulk particle composition to show

Published by Copernicus Publications on behalf of the European Geosciences Union. 
Table 1. List of burns analyzed in this work. ID: Burn ID as catalogued in McMeeking et al. (2009). $\omega_{\text {meas }}$ : single-scattering albedo at $\lambda=532 \mathrm{~nm}$ determined from nephelometer and photoacoustic spectrometer measurements, shown with associated relative uncertainty (Eq. 1).

\begin{tabular}{llll}
\hline ID & Fuel & $\omega_{\text {meas }}$ & Fuel Type \\
\hline 235 & Longleaf pine needles and wire grass (Pinus palustris and Aristida beyrichiana) & $0.934 \pm 0.007$ & trees and grass \\
236 & Black needlerush (Juncus roemerianus) & $0.918 \pm 0.008$ & grass \\
237 & Oak and hickory (Quercus laevis Walt. and Carya nutt) & $0.852 \pm 0.014$ & trees \\
238 & Douglas fir needles and branches, fresh (Pseudotsuga menziesii) & $0.527 \pm 0.028$ & tree \\
239 & Douglas fir needles and branches, dry (Pseudotsuga menziesii) & $0.958 \pm 0.004$ & tree \\
240 & Florida palmetto leaves (Serenoa repens) & $0.428 \pm 0.027$ & southeastern shrub \\
241 & Mississippi palmetto leaves (Serenoa repens) & $0.615 \pm 0.026$ & southeastern shrub \\
242 & Rice straw (Oryza sativa) & $0.890 \pm 0.011$ & Asian fuel \\
243 & Alaskan duff & $0.970 \pm 0.003$ & duff \\
245 & Rhododendron leaves (Rhododendron minus) & $0.809 \pm 0.017$ & southeastern shrub \\
246 & Black spruce needles and branches (Picea mariana) & $0.666 \pm 0.025$ & tree \\
247 & Douglas fir needles and branches, dry (Pseudotsuga menziesii) & $0.975 \pm 0.003$ & tree \\
248 & Alaskan duff & $0.990 \pm 0.001$ & duff \\
249 & Wiregrass (Aristida beyrichiana) & $0.853 \pm 0.014$ & grass \\
250 & Chamise (Adenstoma fasciculatum) & $0.429 \pm 0.027$ & desert shrub \\
251 & Black needlerush (Juncus roemerianus) & $0.900 \pm 0.010$ & grass \\
252 & Sagebrush (Artemisia tridentate) & $0.701 \pm 0.023$ & desert shrub \\
253 & Longleaf pine needles (Pinus palustris) & $0.951 \pm 0.005$ & tree \\
254 & Gallberry (Ilex coriacea Ilex glabra) & $0.446 \pm 0.028$ & southeastern shrub \\
255 & Sugarcane (Saccharum officenarum) & $0.696 \pm 0.023$ & Asian fuel \\
256 & White spruce (Picea glauca) & $0.910 \pm 0.009$ & tree \\
\end{tabular}

the extent to which simple assumptions can be used to model scattering and absorption coefficients.

\section{Experimental}

The Fire Laboratory at Missoula Experiments (FLAME) were performed at the US Forest Service's Fire Science Laboratry (FSL) in Missoula, Montana, and were designed specifically to address data gaps in characterization of gas- and particulate-phase emissions from fuels commonly burned in the United States during wildfires and prescribed burns. The wide variety of fuels burned also provided an opportunity to investigate the range of optical properties of aerosols produced by biomass burning and to seek relationships between the physical and optical properties of the aerosols. McMeeking et al. (2009) provide a complete description of the fuels, burn conditions, instrumentation, analytical methods, and gas- and particulate-phase emission factors for both the FLAME 1 (2006) and FLAME 2 (2007) studies. In this work, we report data from the FLAME 2 study, which was conducted May 20 to June 6, 2007, and specifically from the chamber burn portion of the study which was designed to obtain data for an optical closure study.

During FLAME 2, a total of 21 chamber burns were performed using 18 fuels; two fuels were burned twice, and several fuels were burned in mixtures (Table 1). Approxi- mately $200 \mathrm{~g}$ of each fuel or fuel mixture were ignited and allowed to burn completely, with the emissions filling the sealed combustion chamber $(12.5 \times 12.5 \times 19.5 \mathrm{~m})$. As shown by McMeeking et al. (2009), the emissions were well-mixed through the volume within about $30 \mathrm{~min}$ after ignition. Emissions were continuously sampled from the combustion chamber into a $\sim 2001$ drum at a flow rate of $\sim 1000 \mathrm{lpm}$, and $\sim 200 \mathrm{lpm}$ were sampled from the drum into an adjacent laboratory which housed our instrumentation. A sampling manifold pulled $\sim 30 \mathrm{lpm}$ from this stream and supplied continuous samples to each instrument used in this work. Total residence time of the sample between the chamber and our instruments was approximately $25 \mathrm{~s}$. Emissions were typically sampled for two hours before the chamber was diluted with clean outside air and prepared for the next experiment. The aerosol samples had values of $\mathrm{RH}<35 \%$ at the points of measurement.

We made simultaneous measurements of scattering and absorption coefficients, aerosol size distribution, and aerosol composition. Measurements of the absorption coefficient, $b_{\text {abs, }}$, were made every two minutes using a photoacoustic spectrometer (PAS) operating at $532 \mathrm{~nm}$ (Arnott et al., 1999, 2000; Lewis, et al., 2008). The PAS was calibrated as described by Arnott et al. (2000) prior to the FLAME 2 study using ammonium sulfate and kerosene smoke aerosol particles. Scattering coefficient, $b_{\text {scat }}$, measurements were made using a three wavelength nephelometer (TSI 3563) operating at 450,550 , and $700 \mathrm{~nm}$. The nephelometer was 
calibrated using filtered air, $\mathrm{CO}_{2}$, and $\mathrm{HFC} 134 \mathrm{a}$ gas prior to the study (Anderson and Ogren, 1998), and the calibrations were checked again at the conclusion of the study. Values of $b_{\text {scat }}$ were measured every two seconds and interpolated to $532 \mathrm{~nm}$ using the observed Ångström scattering exponent between 450 and $550 \mathrm{~nm}$. Corrections to measured $b_{\text {scat }}$ also were made for angular non-idealities following Anderson and Ogren (1998), assuming only submicron particles were present. Measurements of $b_{\text {scat }}$ and $b_{\text {abs }}$ were averaged over 10-min intervals to match the sampling times of size distributions.

Aerosol size distributions were measured using the Colorado State University aerosol sizing rack (Hand and Kreidenweis, 2002), which included a differential mobility particle sizer (DMPS; TSI 3081 differential mobility analyzer with TSI 3785 water-based condensation particle counter) and an optical particle counter (OPC; PMS Lasair 1003). The DMPS scans were conducted during $10 \mathrm{~min}$ intervals and a mobility diameter range from 0.04 to $0.63 \mu \mathrm{m}$. OPC data were acquired in six channels, from nominal sizes of 0.2 to $2.0 \mu \mathrm{m}$, during the same time interval. As discussed in detail in Levin et al. (2010), size distributions were constructed for the diameter range of 0.04 to $2.0 \mu \mathrm{m}$ from the combined DMPS+OPC data set using the alignment method of Hand and Kreidenweis (2002). Since highly absorbing aerosols cause the OPC to underestimate particle size, leading to biased size distributions, some of the resulting aligned distributions did not pass quality control checks, and the DMPS-only size distributions were instead used in this work, as explained further below.

Samples of particulate matter with aerodynamic diameters less than $2.5\left(\mathrm{PM}_{2.5}\right)$ and $10 \mu \mathrm{m}\left(\mathrm{PM}_{10}\right)$ were collected onto Teflon $\AA$, nylon, and quartz filters during each burn using the IMPROVE sampler and analyzed for mass concentrations of inorganic ions, organic carbon (OC), elemental carbon (EC), and elements. Carbon analyses for these samples followed the thermal-optical reflectance (TOR) protocol used in the IMPROVE network (Chow, et al., 1993, 2004, 2007). The Teflon $®$ filters were weighed before and after each experiment to determine total gravimetric mass under approximately dry conditions (relative humidity, $\mathrm{RH} \leq 40 \%$ ). Additionally, a high volume sampler (Hi-Vol) with a $\mathrm{PM}_{2.5}$ size cut collected samples on quartz fiber filters. Filter punches from the Hi-Vol samples were analyzed by a Sunset Labs carbon analyzer using the thermal-optical tranmission (NIOSH) protocol (Bae, et al., 2004) to obtain measurements of OC and EC mass concentrations, as described in Sullivan et al. (2008). Although total carbon aerosol concentrations from the two methods agreed well, they differed significantly in the fractions assigned to OC and EC (McMeeking, et al., 2009). Complete descriptions of the aerosol size distribution measurements and of the derivation of aerosol composition using the filter-based data are provided in Levin et al (2010).

www.atmos-chem-phys.net/10/9017/2010/
Scattering coefficient, absorption coefficient, and size distribution data were not used during periods where concentrations were rapidly changing, such as at the start of the burn. Further, some of the instrument responses were saturated at the beginning of burns when aerosol concentrations were high, and these data points also were removed from our analyses. Since on average each burn sampling period lasted two hours (combustion of the fuel typically was completed within 5-15 minutes), the 10-minute resolution of our data led to a maximum number $(N)$ of 12 data points for each experiment.

\section{Results and discussion}

\subsection{Measured single scattering albedos}

Single scattering albedo, $\omega$, is the ratio of the aerosol scattering coefficient, $b_{\text {scat }}$, to the total extinction coefficient, $b_{\text {ext }}$, where $b_{\text {ext }}$ is the sum of scattering and absorption coefficients, $b_{\text {scat }}+b_{\text {abs. }}$. In this study, we estimated $\omega$ in two ways: first, by directly calculating it from measured scattering and absorption coefficients ( $\left.\omega_{\text {meas }}\right)$ and second, by computing it using measured size distributions and estimated refractive indices $\left(\omega_{\text {calc }}\right)$, as explained in Sect. 3.2.

Although particle number and mass concentrations and measured values of $b_{\text {scat }}$ and $b_{\text {abs }}$ decreased during the course of each experiment, calculated values of $\omega_{\text {meas }}$ were relatively constant with time, with the mean standard deviation during an experiment ranging from \pm 0.002 to \pm 0.028 . We thus report a value of $\omega_{\text {meas }}$ for each experiment that has been averaged for all valid sampling times. The relative uncertainty in $\omega_{\text {meas }}$ was calculated as

$\Delta \omega_{\text {meas }}=$

$\sqrt{\left(\frac{b_{\text {scat }}}{\left(b_{\text {scat }}+b_{\text {abs }}\right)^{2}} \Delta b_{\text {abs }}\right)^{2}+\left(\frac{b_{\text {abs }}}{\left(b_{\text {scat }}+b_{\text {abs }}\right)^{2}} \Delta b_{\text {scat }}\right)^{2}}$

where $\Delta b_{\text {scat }}$ was assumed to be $\pm 10 \%$ (Anderson et al., 1996) and $\Delta b_{\text {abs }} \pm 5 \%$ (Lewis et al., 2008). Calculated values of $\omega_{\text {meas }}$ for the chamber burns are listed in Table 1. Values ranged from 0.428 to 0.990 . Fuel species/samples burned in multiple experiments demonstrated consistency between replicate measurements of $\omega$. Smoke from two separate burns of Alaskan duff had $\omega_{\text {meas }}$ of 0.970 and 0.990 , and the aerosols from two black needlerush burns had $\omega_{\text {meas }}$ of 0.918 and 0.900 . Longleaf pine needles and wiregrass were each burned separately producing smoke with $\omega_{\text {meas }}$ values of 0.951 and 0.853 , respectively, while a mixture of the two fuels produced aerosols with a $\omega_{\text {meas }}$ of 0.934 , between that of the individual fuels. Douglas fir needles and branches were burned three times: twice using dry fuel and producing $\omega_{\text {meas }}$ values of 0.958 and 0.975 , and once using fresh fir needles and branches, which produced smoke with $\omega_{\text {meas }}$ of 0.527 . The relatively large difference in values of $\omega_{\text {meas }}$ obtained for dry and fresh Douglas fir samples indicates that 
the condition of the fuel and subsequent combustion conditions play a large role in determining optical properties of emitted aerosols. It is also interesting to note differences in $\omega_{\text {meas }}$ for samples of palmetto leaves obtained from Florida $\left(\omega_{\text {meas }}=0.428\right)$ and Mississippi $\left(\omega_{\text {meas }}=0.615\right)$. As shown in Levin et al. (2010), chemical compositions of these two smokes were also somewhat different, leading to this difference in $\omega_{\text {meas }}$.

It is well known that particulate emissions vary considerably between the flaming and smoldering phases of combustion (McMeeking, et al., 2009), and Reid et al. (2005) suggested relationships between combustion conditions and the $\omega$ of smoke aerosol. McMeeking et al. (2009) used the fire-integrated modified combustion efficiency (MCE; Ward and Radke, 1993) as an indicator of combustion conditions dominating the burn, where MCE is the ratio of molar concentration of $\mathrm{CO}_{2}$ to the molar concentrations of $\mathrm{CO}_{2}+$ $\mathrm{CO}$ in emissions. MCE values lower than $\sim 0.8$ indicate predominantly smoldering phase conditions; MCE values higher than $\sim 0.9$ indicate flaming phase-dominated combustion. We found no correlation $\left(r^{2}=0.006\right)$ between $\omega_{\text {meas }}$ and fire-integrated MCE values for the FLAME 2 chamber burns, consistent with our observations that the relationship between MCE and the ratio of EC to total aerosol carbon was not strong (McMeeking et al., 2009). Furthermore, each of the chamber experiments included a mix of smoke from flaming and smoldering phases, preventing a clear examination of the relationship between combustion phase and optical properties. Reid et al. (2005) also showed that $\omega_{\text {meas }}$ was dependent on type and origin of the fuel. For the limited number of samples we obtained, the combustion of southeastern and desert shrubs yielded aerosols with lower $\omega_{\text {meas }}$ than the other fuels; duff, fir, and pine samples yielded aerosols with the highest $\omega_{\text {meas }}$. We explore the links with smoke aerosol chemical composition in Sect. 3.3.

\subsection{Retrieval of refractive indices}

As demonstrated by Riziq et al. (2007), it is possible to deduce the complex index of refraction of an aerosol sample if simultaneous measurements of size distributions, scattering coefficients, and extinction or absorption coefficients are available. This method relies on applicability of Mie theory, including the assumption of spherical particles and chemical homogeneity of the sample. Our simultaneous measurements of aerosol size distributions, $b_{\text {scat }}$, and $b_{\text {abs }}$ were used in a method similar to that of Riziq et al. (2007) to retrieve bestfit complex refractive indices for our experiments. Values of $b_{\text {scat }}$ and $b_{\text {abs }}$ were calculated using a Mie routine and the measured size distributions for an array of assumed complex refractive indices, $m=n+i k$. Components of the complex refractive index varied between $1.0<n<2.5$ and $0<k<0.7$ for 400 values each of $n$ and $k$. We determined the best-fit index of refraction by finding the global minimum of the merit function $\chi^{2} / N$ within the $n, k$ parameter space defined above
(Riziq, et al., 2007, Dinar, et al., 2008), where $N$ is the number of measurements and $\chi^{2}$ is the chi-square function:

$\chi^{2}=\sum_{j=1}^{2} \sum_{i=1}^{N} \frac{\left(y_{\text {meas }}-y_{\text {calc }}\right)_{i, j}^{2}}{\varepsilon_{i, j_{\text {meas }}}^{2}+\varepsilon_{i, j_{\text {calc }}}^{2}}$

For this study, $y_{\text {meas }}$ was the measured value of interest (i.e., $b_{\text {scat }}$ or $\left.b_{\text {abs }}\right), y_{\text {calc }}$ the corresponding calculated value, $\varepsilon_{\text {meas }}$ the uncertainty associated with the measured quantity, and $\varepsilon_{\text {calc }}$ the uncertainty associated with the calculated quantity. Uncertainties in the retrieved values of $n$ and $k$ were determined as the values which fell within $1 \sigma$ of the minimum $\chi^{2}$, as described by Dinar et al. (2008).

At the start of the study, we conducted a calibration test using ammonium sulfate $\left(\mathrm{NH}_{4}\right)_{2} \mathrm{SO}_{4}$ aerosol, a salt which when aerosolized from aqueous solution and dried produces purely scattering, nearly-spherical particles of known density and refractive index (Mikhailov et al., 2009). The aerosol was generated into the upstream drum, sampled, and characterized in the same way as were the smoke samples. We computed the expected $b_{\text {scat }}$ from measured size distributions, using the literature value of refractive index at $532 \mathrm{~nm}$, $m=1.535+0 i$ (Garland et al., 2007). This calculated $b_{\text {scat }}$ was well-correlated with $b_{\text {scat }}$ measured by the nephelometer $\left(r^{2}=0.99\right)$ after correcting for calibration and truncation errors as described in Sect. 2. Calculations were lower than measurements by about $12 \%$, however, possibly due to different particle losses between the manifold and instrument inlets in the sampling trains for the two instruments. Therefore, we adjusted all of the measured size distributions, for both the calibrations and experiments, by dividing by a factor of 0.884 . Using these adjusted aerosol size distributions and measured values of $b_{\text {scat }}$ at $532 \mathrm{~nm}$ in Eq. (2), we retrieved a refractive index of $1.538 \pm 0.026+0 i$, in excellent agreement with the expected value. When including measurements of $b_{\text {abs, }}$, which were close to zero, in the retrieval, we obtained $1.541 \pm 0.026+0.0003 i \pm 0.00003$. Although a constant correction factor attributed to particle losses was applied to all size distributions, including for smoke, particle losses may have varied among burns depending on mean size and particle shape. We have not attempted to account for this. It is also possible that the need for the correction factor arose for a reason other than particle losses: an offset in the nephelometer calibrations, for example. If the correction factor should have been applied to the nephelometer measurements instead, the $\omega_{\text {meas }}$ reported in Table 1 are too low, and our subsequent comparisons also are affected. These considerations introduce some additional uncertainty into our analyses.

We next applied Eq. (2) to retrieve best-fit refractive indices from our measurements of $b_{\text {scat }}$ and $b_{\text {abs }}$ for smoke aerosols. We selected six cases of varying $\omega_{\text {meas }}$ for refractive index retrieval, as shown in Table 2. Table 2 indicates whether DMPS data alone, or aligned DMPS+OPC data, were used to construct the volume size distribution in each 

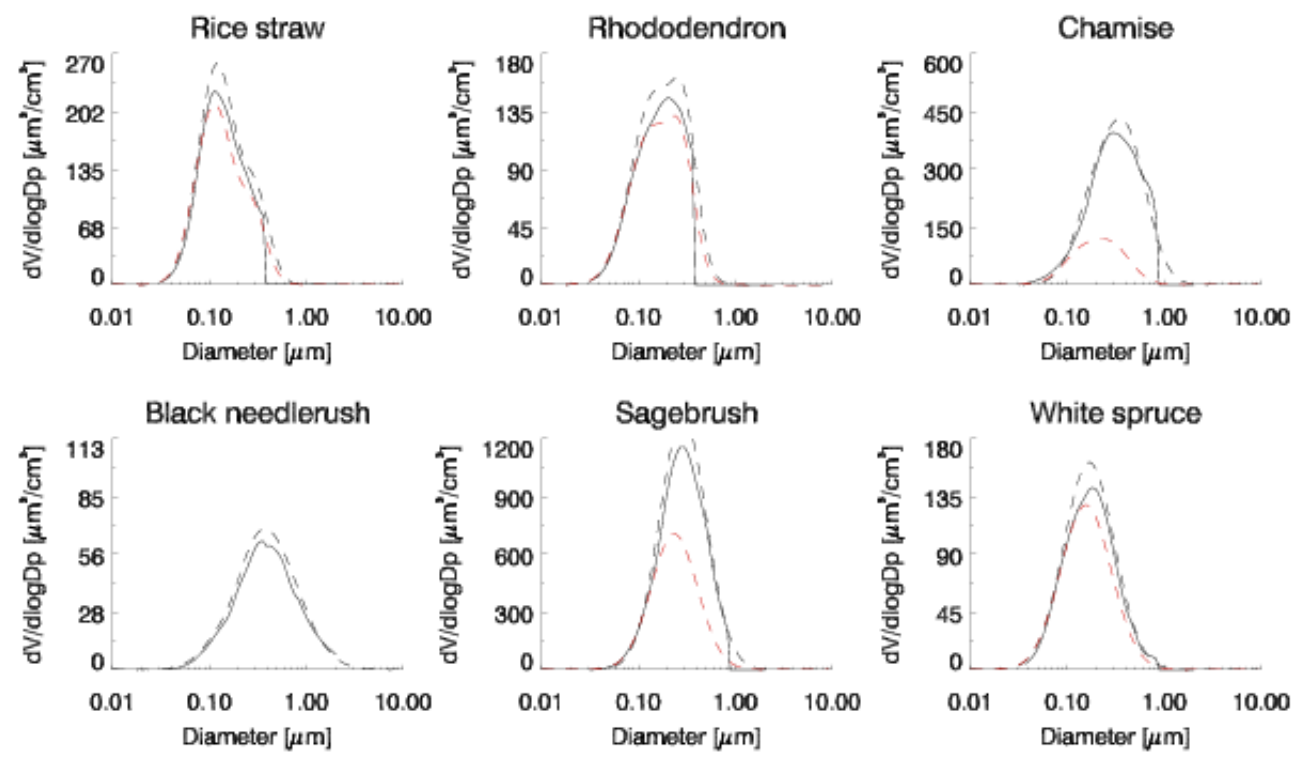

Fig. 1. Examples of measured aerosol size distributions (solid black lines) for six selected experiments. The dashed black lines indicate the lognormal fit size distributions. The dashed red lines indicate the lognormal fits for size distributions after adjusting by the shape factors shown in Table 2.

Table 2. Retrieved complex refractive indices ( $n$ and $k$ ) and $\omega_{\text {meas }}$ for selected burns, using lognormal distribution fits to the aligned volume size distributions after shifting by the appropriate shape factor. The fit lognormal distribution is indicated as monomodal (M) or bimodal (B); $N$ is the number of samples for which the fit was minimized; and $\chi / \mathrm{N}$ the merit function for that experiment. The eighth column indicates an estimate of the shape factor obtained by comparing total mass concentrations derived from gravimetric filter measurements with those calculated from size distributions and estimated densities (see text). The final column indicates the shape factor applied to derive the complex refractive indices in columns 6 and 7, and also used in construction of Fig. 3.

\begin{tabular}{|c|c|c|c|c|c|c|c|c|}
\hline Fuel & Distribution type & Fit & $N$ & $\chi / N$ & $n$ & $k$ & $\begin{array}{l}\text { Ratio of } \\
\text { calculated to } \\
\text { gravimetric } \\
\text { mass concentration }\end{array}$ & $\begin{array}{l}\text { Shape factor } \\
\text { applied in this } \\
\text { work }\end{array}$ \\
\hline Rice straw & DMPS-only & $\mathrm{B}$ & 10 & 0.141 & $1.538 \pm 0.053$ & $0.012 \pm 0.001$ & 0.99 & 1.07 \\
\hline Rhododendron leaves & DMPS-only & $\mathrm{B}$ & 10 & 0.222 & $1.564 \pm 0.053$ & $0.030 \pm 0.003$ & 1.0 & 1.07 \\
\hline Chamise & DMPS-only & $\mathrm{B}$ & 8 & 6.32 & $1.605 \pm 0.071$ & $0.217 \pm 0.027$ & 1.5 & 1.55 \\
\hline Black needlerush & $\mathrm{DMPS}+\mathrm{OPC}$ & $\mathrm{B}$ & 5 & 0.582 & $1.579 \pm 0.090$ & $0.019 \pm 0.002$ & 0.79 & 1.0 \\
\hline Sagebrush & DMPS-only & M & 18 & 0.018 & $1.665 \pm 0.071$ & $0.086 \pm 0.009$ & 1.0 & 1.23 \\
\hline Alaskan white spruce & DMPS-only & M & 7 & 0.572 & $1.553 \pm 0.053$ & $0.011 \pm 0.001$ & 0.91 & 1.08 \\
\hline
\end{tabular}

experiment. Sample volume distributions are shown in Fig. 1 (solid black lines). As can be seen from Fig. 1, in some instances the size range of the measurements did not extend to large enough sizes to fully describe the main mode of $\mathrm{PM}_{2.5}$ volume distribution. To help fill this gap, volume distributions for each valid 10-min sample were fit with monomodal or bimodal lognormal distributions, depending on the best fit to the data (Table 2, and dashed black lines in Fig. 1). We then converted the fitted volume distributions to number distributions assuming particle sphericity and used these number distributions in the Mie calculations. Finally, for each burn, we retrieved a best-fit complex refractive index for each individual size distribution measurement ( $N=1$ in Eq. 2$)$, as well as a single-best fit refractive index for all size distributions for that burn ( $N$ in Eq. (2) set to the value indicated in Table 2). As a sensitivity test, we applied known counting uncertainties to size distributions and found that these had no measurable effects on the retrieved refractive indices. Similarly to what was observed for $\omega_{\text {meas }}$, individual retrieved values of refractive index did not vary much during an experiment and only the value retrieved by minimizing the error for the entire sample is reported. Retrieved refractive indices corresponding to shape factors $=1$ (spherical particles assumption) are plotted as blue symbols in Fig. 2. 

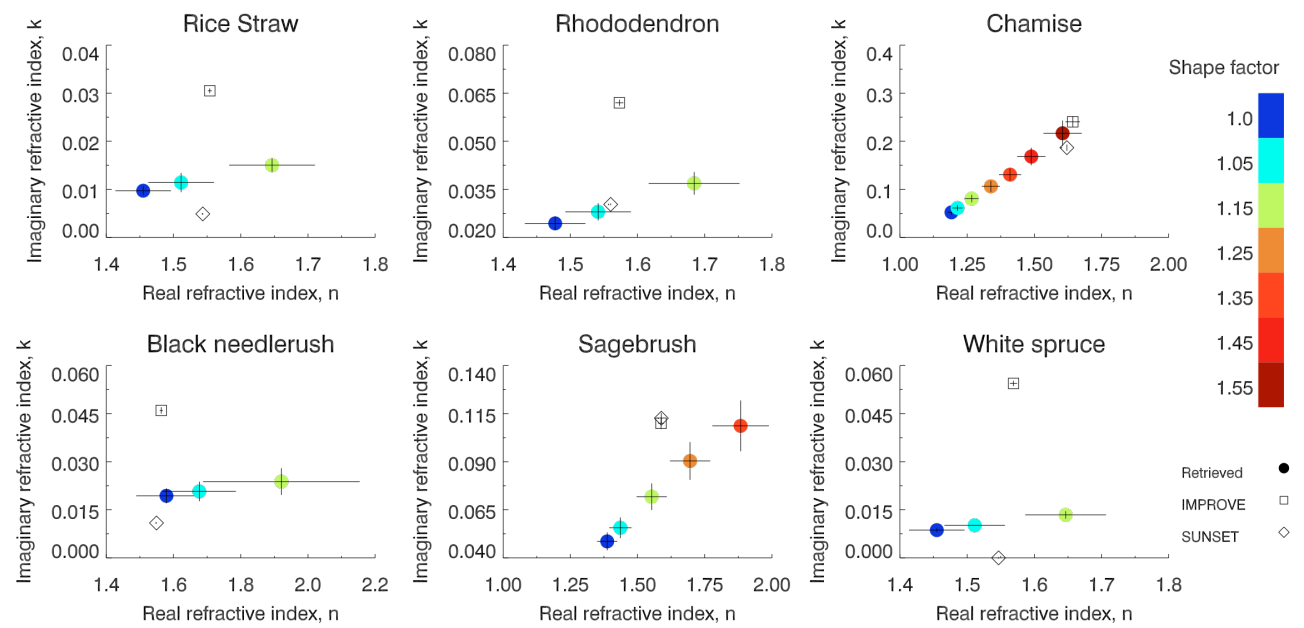

Fig. 2. Sensitivity of the retrieved real and imaginary components of refractive index (colored circles) to shifts in the measured size distribution (color bar indicates applied shape factor used to estimate effects of nonsphericity). The refractive index values computed from composition are shown as black squares and diamonds, depending on the protocol used to obtain OC and EC concentrations. ${ }^{*}$ Horizontal and vertical error bars indicate uncertainties in retrieved real and imaginary refractive indices.

It is well-known that combustion particles are often not spherical in shape (Slowik, et al., 2004; Chakrabarty, et al., 2006). Nonsphericity leads to overestimates of size in the DMPS (DeCarlo, et al., 2004; Slowik, et al., 2004) and has an uncertain effect in OPC sizing. We tested sensitivity of the retrieval to the input size distribution by dividing all diameters in the lognormal fit distribution by assumed shape factors of 1.05 to 1.55 , in increments of 0.1 , and then rerunning the retrieval algorithm, resulting in a series of best-fit pairs of $n, k$ for each experiment (Fig. 2). We note that using an assumed shape factor to simply shift the distributions that were obtained by inverting data under the assumption of particle sphericity generates only an approximate estimate of the corrected size distributions (red lines in Fig. 1), since nonsphericity affects the instrument response and should properly be considered in inversion of the raw data. The strong sensitivity of the retrieved refractive index to the aerosol size distribution is immediately apparent in Fig. 2. For example, applying a relatively small shape factor of 1.05 produced a $1-5 \%$ increase in the retrieved real refractive index, $n$, and a corresponding $10-18 \%$ increase in the imaginary refractive index, $k$; the differences were larger for larger shape corrections.

There is additional evidence of particle nonsphericity in FLAME smoke particle samples. Hand et al. (2010) used volume size distributions, calculated from number size distributions measured with the same DMPS system used here, and composition-derived densities from the FLAME 1 (2006) chamber burn experiments to estimate aerosol mass concentrations, and compared these to the gravimetric mass determined from filter experiments. In some cases, the computed mass was $60-80 \%$ higher than measured, outside any reasonable uncertainty bounds, indicating that the size distri- bution measurements were biased (particles sized too large), most likely because of the presence of nonspherical particles. Hand et al. (2010) used these ratios as estimates of the true shape factors and adjusted the size distributions accordingly. In Table 2, we present the ratios of calculated to gravimetric mass concentrations for all six selected experiments, using the size distributions derived assuming a shape factor of 1 . We found that this ratio for the chamise experiment was $\sim 1.5$ times the measured gravimetric mass concentration, consistent with the factor of 1.6 applied to the FLAME 1 chamise burn studied by Hand et al. (2010). These values of shape factor are in reasonable agreement with prior published estimates. For example, Slowik et al. (2004) and Park et al. (2004) found shape factors of 1.5 and larger for soot particles. In contrast, the mass concentration ratio computed for our black needlerush experiment was 0.79 , indicating that the size distributions grossly underestimated aerosol mass concentrations, most likely because some large particles were not properly sized or were missed entirely when the DMPS data alone were used to construct the $\mathrm{PM}_{2.5}$ volume distribution. Finally, we note that nonsphericity also will affect scattering and absorption measurements, including the nephelometer truncation correction. We have not attempted any corrections for nonsphericity in those optical data.

\subsection{Calculation of refractive indices from composition}

Following the approach outlined in Levin et al. (2010), we assumed measured $\mathrm{PM}_{2.5}$ constituents were present as the chemical species with the properties listed in Table 3. Further, we assumed all species were internally mixed and that the particles had zero water content, and used aerosol composition data and a volume-weighted mixing rule to calculate the real $\left(n_{\text {comp }}\right)$ and imaginary $\left(k_{\text {comp }}\right)$ indices of refraction. 
Table 3. Assumed densities and refractive indices used to calculate $n_{\text {comp }}$ and $k_{\text {comp. }}$

\begin{tabular}{lll}
\hline Species & Density $\left[\mathrm{g} \mathrm{cm}^{-3}\right]$ & Refractive index \\
\hline $\mathrm{KCl}$ & $1.99^{\mathrm{a}}$ & $1.49^{\mathrm{a}}$ \\
$\mathrm{K}_{2} \mathrm{SO}_{4}$ & $2.66^{\mathrm{a}}$ & $1.50^{\mathrm{a}}$ \\
$\mathrm{KNO}_{3}$ & $2.11^{\mathrm{a}}$ & $1.50^{\mathrm{a}}$ \\
$\mathrm{NH}_{4} \mathrm{Cl}$ & $1.53^{\mathrm{a}}$ & $1.55^{\mathrm{a}}$ \\
$\mathrm{NaCl}$ & $2.16^{\mathrm{a}}$ & $1.54^{\mathrm{a}}$ \\
$\left.\mathrm{NH}_{4}\right)_{2} \mathrm{SO}_{4}$ & $1.76^{\mathrm{b}}$ & $1.535^{\mathrm{c}}$ \\
$\mathrm{Al}_{2} \mathrm{O}_{3}$ & $3.97^{\mathrm{a}}$ & $1.77^{\mathrm{a}}$ \\
$\mathrm{CaO}$ & $3.30^{\mathrm{a}}$ & $1.83^{\mathrm{a}}$ \\
Organic Carbon & $1.20^{\mathrm{d}}$ & $1.55^{\mathrm{e}}$ \\
Light Absorbing Carbon & $1.70-2.1^{\mathrm{f}}$ & $1.75-0.63 \mathrm{i}-1.95-0.79 \mathrm{i}^{\mathrm{f}}$ \\
\hline
\end{tabular}

${ }^{a}$ Lide (2008), $\lambda=589 \mathrm{~nm} ;{ }^{b}$ Tang (1996); $\lambda=580 \mathrm{~nm} ;{ }^{c}$ Garland et al. (2007); $\lambda=532 \mathrm{~nm}$; ${ }^{\mathrm{d}}$ Turpin and Lim (2001); ${ }^{\mathrm{e}}$ Hand and Kreidenweis (2002); visible range ${ }^{\mathrm{f}}$ Bond and Bergstrom (2006): visible range

The assumed refractive indices of individual species are shown in Table 3. We note that refractive indices have been reported at wavelengths $(\lambda)$ different than the $532 \mathrm{~nm}$ used for our optical data, but we assume no spectral dependence over this range and have not adjusted these values. We also note that zero absorption has been assumed for OC. Schmid et al. (2009) suggest that this assumption is appropriate for Amazonian biomass burning particles at $\lambda>500 \mathrm{~nm}$; and Chakrabarty et al. (2010), working with data from the FLAME studies, attributed only small imaginary parts of the refractive index at $532 \mathrm{~nm}(0.0027$ and 0.0006) to the OC components of Ponderosa pine duff and Alaskan duff smokes, respectively. However, Adler et al. (2010) determined an effective refractive index for OC in fresh diesel soot of $n=1.519+0.048 \mathrm{i}$. Neglecting the potential contribution of $\mathrm{OC}$ to absorption represents an additional source of uncertainty in our calculations. Special consideration has to be given to the choice of density and complex refractive index for EC which has been shown to be dependent on the void fraction present in the sample (Bond and Bergstrom, 2006; Schmid, et al., 2009). All calculations here were done for the upper and lower limits of the range of refractive index/density pairs reported by Bond and Bergstrom, as indicated in Table 3. Further, we used OC and EC concentrations from both the IMPROVE filters/TOR method ( $\left.n_{\text {comp_IMPROVE }}, k_{\text {comp_IMPROVE }}\right)$ and from the hivol filters/NIOSH protocol $\left(n_{\text {comp_Sunset }}, k_{\text {comp_Sunset }}\right)$. These separate estimates are shown in Fig. 2 as squares and diamonds, with uncertainty bars indicating the ranges obtained for the two assumed EC properties, as discussed above. The choice of EC properties had a negligible influence on the computed refractive indices for these cases, whereas the differences due to the fraction of total carbonaceous aerosol attributed to EC and OC by the two analysis methods were large for most of the cases.
Comparing the computed and retrieved values in Fig. 2, only in the black needlerush burn was the retrieved real refractive index under the spherical-particles assumption (shape factor=1) smaller than or close to that computed from composition. As shown in Table 2, the black needlerush size distributions very likely underestimated total aerosol mass concentration. To compensate, the retrieval was forced to a large real refractive index $(\sim 1.6$, larger than in the other five cases), since increases in $n$ increase the computed scattering coefficients. The shape factors estimated from mass concentration ratios for the rice straw, rhododendron, and white spruce experiments (Table 2) were within 10\% of unity, which is consistent with the agreement between the optical properties computed for assumed shape factors between 1.05 and 1.1 and those computed from composition. In contrast, the retrieved real refractive indices for shape factor $=1$ for the chamise and sagebrush burns, $n<1.4$, were much lower than expected based on composition. We already have noted that the chamise volume distributions were overestimated because of the presence of nonspherical particles. The mass concentration ratio for sagebrush was very close to 1 (Table 2), suggesting shape factors deviated from unity by less than $\sim 10 \%$. However, this was contradicted by measured optical properties: the $\omega_{\text {meas }}$ of 0.701 was the second lowest of the six cases, indicating a high likelihood that non-spherical particles were present (Chakrabarty, et al., 2006). For both the chamise and sagebrush burns, high absorption led to inaccurate OPC sizing, as explained in Levin et al. (2010), and DMPS-only distributions were used in our calculations. The computed volume distributions for those burns in particular are thus subject to two strong, but counteracting, biases: they are expected to be overestimated because of the presence of nonspherical particles, and underestimated if significant number concentrations of particles larger than $\sim 630 \mathrm{~nm}$, that are outside the range of the DMPS, are present. Depending on the net effects of these influences on the estimated volume distributions, the resulting impacts on computed optical properties also can be in either direction, toward over- or 
underestimates of the real refractive index required to match observed $b_{\text {scat }}$. We note that the composition-derived real refractive indices for sagebrush and chamise are consistent with those retrieved for shape factors of $\sim 1.23$ and 1.55 , respectively, and that these shape factors are not unreasonable, based on available observations. Indeed, for all six cases, the real refractive indices computed from the composition data appear to be good estimates of those required to match observed $b_{\text {scat }}$ for reasonable choices of shape factors (last column, Table 2).

In general, the retrieved values of the imaginary component of the refractive index, $k$, did not match those computed from chemical composition. Although the choice of carbon analysis method led to little difference between $n_{\text {comp_Sunset }}$ and $n_{\text {comp_IMPROVE, }}$, there were large differences between $k_{\text {comp_Sunset }}$ and $k_{\text {comp_IMPROVE }}$, except for the sagebrush sample. $k_{\text {comp_IMPROVE }}$ was typically larger than $k_{\text {comp_Sunset }}$, reflecting the larger fraction of total carbon mass assigned to EC by the IMPROVE protocol (Chow, et al., 2004). For the choices of shape factors listed in the last column of Table 2, retrieved $k$ was closer to $k_{\text {comp_Sunset }}$ in most cases.

All of the estimates shown in Fig. 2 assume an internallymixed aerosol. We checked the effects of this assumption by computing $\omega$ from measured aerosol composition using internal- and external-mixture aerosol models. For both models, we adjusted the size distributions by the shape factors shown in the last column of Table 2, which were selected to yield agreement between retrieved real refractive indices and those calculated from composition. The internal mixture model used these adjusted size distributions and complex refractive indices derived from composition to calculate the average $\omega$ for each experiment. The external-mixture model used a calculated mass extinction efficiency (MEE) and mass absorption efficiency (MAE) for each species individually, applied to measured species mass concentrations, to estimate $\omega$. MEE and MAE were evaluated by computing $b_{\text {ext }}$ and $b_{\text {abs }}$ for each species using the properties in Table 3 and assuming unit mass distributed as a function of diameter according to the adjusted size distributions.

Figure 3 shows measured $\omega$ together with results of the internal- and external-mixture model calculations of $\omega$ (symbol color) for the IMPROVE and Sunset values of OC and EC (symbol shape) and for the range of complex refractive indices and densities reported by Bond and Bergstrom (2006) for EC (horizontal error bars). As expected, the internalmixture model always produces an estimate of $\omega$ lower than that from the external-mixture model. The variability in differences between the computed refractive indices applied in the internal-mixture models and retrieved refractive indices that match $\omega_{\text {meas }}$ (Fig. 2) is reflected in variability between the measurements and models in Fig. 3. For example, the internal-mixture model using the EC/OC splits derived from the IMPROVE protocol produced the darkest aerosol and had the poorest agreement with $\omega_{\text {meas }}$, except for the chamise sample.

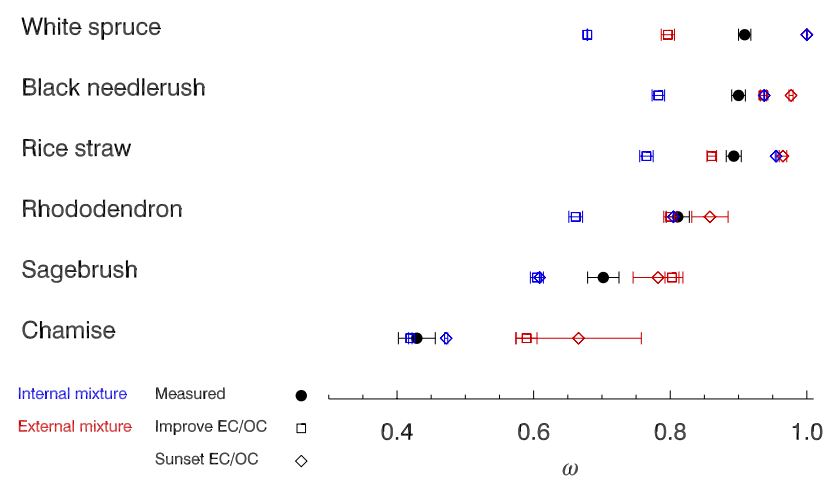

Fig. 3. Values of $\omega_{\text {meas }}$ derived from measured values of aerosol scattering and absorption coefficients (black circles). Blue and red symbols indicate $\omega$ calculated from aerosol composition using external (blue) and internal (red) mixture models, for two measurements of carbonaceous components: EC/OC values from the IMPROVE filters and TOR protocol (squares) and EC/OC values from the hi-vol filters analyzed by the Sunset instrument and NIOSH protocol (diamonds). Horizontal bars indicate the range of values produced by the extremes of EC properties (Table 3). In the composition-based calculations, size distributions applied were those shifted by the shape factors indicated in Table 2 .

\section{Summary and conclusions}

Our findings indicated a great deal of variability in $\omega$ for biomass burning aerosols, attributable partially to fuel composition and condition and partially to combustion conditions. We observed a broad range of $\omega_{\text {meas }}$ values during this study (from 0.428 to 0.990 ) and with good consistency between replicate burns conducted for a particular fuel. We were not able to find a relationship between fire-integrated MCE and $\omega_{\text {meas }}$ for our experiments, in part because the experiment was not designed to clearly distinguish between differences in optical properties of emissions from flaming and smoldering combustion phases.

Measured size distributions were the limiting factor in retrieving refractive indices using direct measurements of $b_{\text {scat }}$, $b_{\text {abs }}$, size distributions, and Mie Theory. Measurement of the size distribution was affected by the presence of absorbing particles in the samples, which caused the OPC to underestimate particle size, and by the presence of nonspherical particles, which caused particles to be oversized in the DMPS and had an unknown effect in the OPC. Our calculations demonstrated that small shifts in measured size distributions, applied to account for particle nonsphericity, had a large impact on the retrieved values of refractive index. Agreement between retrieved real refractive indices and real refractive indices calculated using composition measurements was achieved for reasonable choices of nonsphericity, assuming an internally-mixed aerosol. The retrieved imaginary component of refractive index, however, was generally different from that computed from composition. Values of $k_{\text {retrieved }}$ 
obtained for the nonsphericity corrections that were applied to force agreement between retrieved and compositionderived real refractive indices generally agreed more closely with those computed for the OC/EC split determined by the NIOSH protocol. As also found in prior studies, nonsphericity of the particles limited applicability of both standard aerosol size distribution measurement techniques and of Mie theory to the computation of optical properties. Within these constraints, however, we derived dry refractive indices consistent with $\omega_{\text {meas }}$ having real components of $1.538-1.665$, and imaginary components of $0.011-0.217$.

Measurements of aerosol composition were used to calculate $\omega$ using models for externally and internally mixed aerosols. Measured values of $\omega_{\text {meas }}$ fell between those computed from the two models. Values of $\omega$ calculated using an external-mixture model were consistently higher than those using an internal-mixture model, in agreement with previous work that suggested internal mixtures amplify absorption due to EC (Bond and Bergstrom, 2006).

The observed range in $\omega_{\text {meas }}$ in this study agrees with the range in the literature (Reid, et al., 2005), although we had a larger number of observations with $\omega_{\text {meas }}<0.7$ than those authors reported. The $\omega_{\text {meas }}$ observed in near-source laboratory sampling as represented by the FLAME experiments does not capture the effects on the aerosol optical properties of water uptake or of aging processes that lead to deposition of secondary material. Addition of water and/or secondary species is expected to lead to increases in the visible wavelength $\omega$ of smoke aerosol (Reid, et al., 2005). While the values of $\omega_{\text {meas }}$ reported here, particularly for the more highly absorbing samples, may not be applicable to ambient plumes or to aged smoke hazes, they are expected to represent an initial starting point for aerosol optical properties. These initial conditions are useful for validation of predictions of the evolution of smoke aerosol optical properties with age, and the resulting effects on direct aerosol forcing and visibility.

Acknowledgements. This research was supported by the US Department of Energy's Office of Science (BER) through the Western Regional Center of the National Institute for Climatic Change Research, Grant number MPC35TA-A4. The FLAME studies were supported by the US Joint Fire Science Program under JFSP Project Number 05-3-1-06 and by the National Park Service. The authors gratefully acknowledge the assistance of the many individuals who secured fuel samples for this work and helped conduct the burns. We also thank the Joint Fire Science Program and American Association for Aerosol Research for assisting with publication costs through their support of the Biomass Burning Symposium at the 2009 Annual Meeting of the AAAR.

Edited by: A. Chen

\section{References}

Adler, G., Riziq, A. A., Erlick, C. and Rudich, Y.: Effect of intrinsic organic carbon on the optical properties of fresh diesel soot, Proc. Natl. Acad. Sci. USA, 107, 6699-6704, 2010.

Anderson, T. L., Covert, D. S., Marshall, S. F., Laucks, M. L., Charlson, R. J., Waggoner, A. P., Ogren, J. A., Caldow, R., Holm, R. L., Quant, F. R., Sem, G. J., Wiedensohler, A., Ahlquist, N. A., and Bates, T. S.: Performance characteristics of a high-sensitivity, three-wavelength, total scatter/backscatter nephelometer, J. Atmos. Ocean. Technol., 13, 967-986, 1996.

Anderson, T. L. and Ogren, J. A.: Determining aerosol radiative properties using the TSI 3563 integrating nephelometer, Aerosol Sci. Technol., 29, 57-69, 1998.

Arnott, W. P., Moosmüller, H., Rogers, C. F., Jin, T. F. and Bruch, R.: Photoacoustic spectrometer for measuring light absorption by aerosol: instrument description, Atmos. Environ., 33, 28452852, 1999.

Arnott, W. P., Moosmüller, H. and Walker, J. W.: Nitrogen dioxide and kerosene-flame soot calibration of photoacoustic instruments for measurement of light absorption by aerosols, Rev. Sci. Inst., 71, 4545-4552, 2000.

Bae, M. S., Schauer, J. J., DeMinter, J. T., Turner, J. R., Smith, D., and Cary, R. A.: Validation of a semi-continuous instrument for elemental carbon and organic carbon using a thermal-optical method, Atmos. Environ., 38, 2885-2893, 2004.

Bond, T. C.: Can warming particles enter global climate discussions?, Environ. Res. Lett., 2, 045030, doi:10.1088/17489326/2/4/045030, 2007.

Bond, T. C. and Bergstrom, R. W.: Light absorption by carbonaceous particles: An investigative review, Aerosol Sci. Technol., 40, 27-67, 2006.

Chakrabarty, R. K., Moosmüller, H., Chen, L. W. A., Lewis, K., Arnott, W. P., Mazzoleni, C., Dubey, M. K., Wold, C. E., Hao, W. M., and Kreidenweis, S. M.: Brown carbon in tar balls from smoldering biomass combustion, Atmos. Chem. Phys., 10, 6363-6370, doi:10.5194/acp-10-6363-2010, 2010.

Chakrabarty, R. K., Moosmüller, H., Garro, M. A., Arnott, W. P., Walker, J., Susott, R. A., Babbitt, R. E., Wold, C. E., Lincoln, E. N. and Hao, W. M.: Emissions from the laboratory combustion of wildland fuels: Particle morphology and size, J. Geophys. Res. Atmos., 111, D07204, doi:10.1029/2005JD006659, 2006.

Chen, Y. and Bond, T. C.: Light absorption by organic carbon from wood combustion, Atmos. Chem. Phys., 10, 1773-1787, doi:10.5194/acp-10-1773-2010, 2010.

Chow, J., Watson, J., Chen, L., Arnott, W., and Moosmüller, H.: Equivalence of elemental carbon by thermal/optical reflectance and transmittance with different temperature protocols, Environ. Sci. Technol., 38, 4414-4422, 2004.

Chow, J., Watson, J., Pritchett, L., Pierson, W., Frazier, C., and Purcell, R.: The DRI thermal optical reflectance carbon analysis system - description, evaluation and applications in United-States air-quality studies, Atmos. Environ., 27, 1185-1201, 1993.

Chow, J. C., Watson, J. G., Chen, L. W. A., Chang, M. C. O., Robinson, N. F., Trimble, D., and Kohl, S.: The IMPROVE-A temperature protocol for thermal/optical carbon analysis: maintaining consistency with a long-term database, J. Air Waste Manage. Assoc., 57, 1014-1023, 2007.

Chylek, P. and Wong, J.: Effect of absorbing aerosols on global radiation budget, Geophys. Res. Lett., 22, 929-931, 1995. 
DeCarlo, P. F., Slowik, J. G., Worsnop, D. R., Davidovits, P., and Jimenez, J. L.: Particle morphology and density characterization by combined mobility and aerodynamic diameter measurements. Part 1: Theory, Aerosol Sci. Technol., 38, 1185-1205, 2004.

Dinar, E., Riziq, A. A., Spindler, C., Erlick, C., Kiss, G., and Rudich, Y.: The complex refractive index of atmospheric and model humic-like substances (HULIS) retrieved by a cavity ring down aerosol spectrometer (CRD-AS), Faraday Discuss., 137, 279-295, 2008.

Garland, R. M., Ravishankara, A. R., Lovejoy, E. R., Tolbert, M. A., and Baynard, T.: Parameterization for the relative humidity dependence of light extinction: Organicammonium sulfate aerosol, J. Geophys. Res.-Atmos., 112, D19303, doi:10.1029/2006JD008179, 2007.

Hand, J. L., Day, D. E., McMeeking, G. M., Levin, E. J. T., Carrico, C. M., Kreidenweis, S. M., Malm, W. C., Laskin, A., and Desyaterik, Y.: Measured and modeled humidification factors of fresh smoke particles from biomass burning: role of inorganic constituents, Atmos. Chem. Phys., 10, 6179-6194, doi:10.5194/acp10-6179-2010, 2010.

Hand, J. L. and Kreidenweis, S. M.: A new method for retrieving particle refractive index and effective density from aerosol size distribution data, Aerosol Sci. Technol., 36, 1012-1026, 2002.

Levin, E. J. T., McMeeking, G. R., Carrico, C., Mack, L., Kreidenweis, S. M., Wold, C. E., Moosmüller, H., Arnott, W. P., Hao, W. M., Collett, J. L., and Malm, W. C.: Biomass burning smoke aerosol properties measured during FLAME, in review, J. Geophys. Res.-Atmos., accepted, 2010.

Lewis, K., Arnott, W. P., Moosmüller, H., and Wold, C. E.: Strong spectral variation of biomass smoke light absorption and single scattering albedo observed with a novel dual-wavelength photoacoustic instrument, J. Geophys. Res.-Atmos., 113, D16203, doi:10.1029/2007JD009699, 2008.

Lide, D. R.: CRC handbook of chemistry and physics [a readyreference book of chemical and physical data], CRC Taylor \& Francis, 2008.

Massoli, P., Bates, T. S., Quinn, P. K., Lack, D. A., Baynard, T., Lerner, B. M., Tucker, S. C., Brioude, J., Stohl, A., and Williams, E. J.: Aerosol optical and hygroscopic properties during TexAQS-GoMACCS 2006 and their impact on aerosol direct radiative forcing, J. Geophys. Res.-Atmos., 114, D00F07, doi:10.1029/2008JD011604, 2009.

McMeeking, G. R., Kreidenweis, S. M., Baker, S., Carrico, C. M., Chow, J. C., Collett, J. L., Hao, W. M., Holden, A. S., Kirchstetter, T. W., Malm, W. C., Moosmüller, H., Sullivan, A. P., and Wold, C. E.: Emissions of trace gases and aerosols during the open combustion of biomass in the laboratory, J. Geophys. Res.Atmos., 114, D19210, doi:10.1029/2009JD011836, 2009.

Mikhailov, E., Vlasenko, S., Martin, S. T., Koop, T., and Pöschl, U.: Amorphous and crystalline aerosol particles interacting with water vapor: conceptual framework and experimental evidence for restructuring, phase transitions and kinetic limitations, Atmos. Chem. Phys., 9, 9491-9522, doi:10.5194/acp-9-9491-2009, 2009.

Moosmüller, H., Chakrabarty, R. K. and Arnott, W. P.: Aerosol light absorption and its measurement: A review, J. Quant. Spectrosc. Radiat. Transfer, 110, 844-878, 2009.
Park, K., Kittelson, D. B., and McMurry, P. H.: Structural properties of diesel exhaust particles measured by transmission electron microscopy (TEM): Relationships to particle mass and mobility, Aerosol Sci. Technol., 38, 881-889, 2004.

Ramanathan, V. and Feng, Y.: Air pollution, greenhouse gases and climate change: Global and regional perspectives, Atmos. Environ., 43, 37-50, 2009.

Ramanathan, V., Li, F., Ramana, M. V., Praveen, P. S., Kim, D., Corrigan, C. E., Nguyen, H., Stone, E. A., Schauer, J. J., Carmichael, G. R., Adhikary, B. and Yoon, S. C.: Atmospheric brown clouds: Hemispherical and regional variations in long-range transport, absorption, and radiative forcing, J. Geophys. Res.-Atmos., 112, D22S21, doi:10.1029/2006JD008124, 2007.

Reid, J. S., Eck, T. F., Christopher, S. A., Koppmann, R., Dubovik, O., Eleuterio, D. P., Holben, B. N., Reid, E. A., and Zhang, J.: A review of biomass burning emissions part III: intensive optical properties of biomass burning particles, Atmos. Chem. Phys., 5, 827-849, doi:10.5194/acp-5-827-2005, 2005.

Riziq, A. A., Erlick, C., Dinar, E., and Rudich, Y.: Optical properties of absorbing and non-absorbing aerosols retrieved by cavity ring down (CRD) spectroscopy, Atmos. Chem. Phys., 7, 15231536, doi:10.5194/acp-7-1523-2007, 2007.

Schmid, O., Chand, D., Karg, E., Guyon, P., Frank, G. P., Swietlicki, E., and Andreae, M. O.: Derivation of the Density and Refractive Index of Organic Matter and Elemental Carbon from Closure between Physical and Chemical Aerosol Properties, Environ. Sci. Technol., 43, 1166-1172, 2009.

Slowik, J. G., Stainken, K., Davidovits, P., Williams, L. R., Jayne, J. T., Kolb, C. E., Worsnop, D. R., Rudich, Y., DeCarlo, P. F., and Jimenez, J. L.: Particle morphology and density characterization by combined mobility and aerodynamic diameter measurements. Part 2: Application to combustion-generated soot aerosols as a function of fuel equivalence ratio, Aerosol Sci. Technol., 38, 1206-1222, 2004.

Spindler, C., Riziq, A. A., and Rudich, Y.: Retrieval of aerosol complex refractive index by combining cavity ring down aerosol spectrometer measurements with full size distribution information, Aerosol Sci. Technol., 41, 1011-1017, 2007.

Sullivan, A. P., Holden, A. S., Patterson, L. A., McMeeking, G. R., Kreidenweis, S. M., Malm, W. C., Hao, W. M., Wold, C. E., and Collett, J. L.: A method for smoke marker measurements and its potential application for determining the contribution of biomass burning from wildfires and prescribed fires to ambient $\mathrm{PM}_{2.5}$ organic carbon, J. Geophys. Res.-Atmos., 113, D22302, doi:10.1029/2008JD010216, 2008.

Tang, I. N.: Chemical and size effects of hygroscopic aerosols on light scattering coefficients, J. Geophys. Res. Atmos., 101, 19245-19250, 1996.

Turpin, B. J. and Lim, H. J.: Species contributions to $\mathrm{PM}_{2.5}$ mass concentrations: Revisiting common assumptions for estimating organic mass, Aerosol Sci. Technol., 35, 602-610, 2001.

Ward, D. E. and Radke, L. F.: Emission measurements from vegetation fires: A comparative evaluation of methods and results: Fire in the Environment: The Ecological, Atmospheric, and Climatic Importance of Vegetation Fires, edited by: P. J. Crutzen and J.-G. Goldammer, J. Wiley, Chichester, UK, 53-76, 1993. 